\title{
Family medicine vocational training and career satisfaction in Hong Kong
}

\author{
K. P. Lee ${ }^{1}$, C. Wong ${ }^{1 *}$ (D) D. Chan ${ }^{1}$, K. Kung ${ }^{1}$, L. Luk', M. C. S. Wong ${ }^{1}$, D. Chao ${ }^{2}$, V. Leung ${ }^{2}$, C. W. Chan², W. Ko², \\ T. F. Leung ${ }^{2}$, Y. H. Chan' ${ }^{2}$, H. T. Fung' ${ }^{2}$, M. K. Lee ${ }^{2}$ and S. Y. S. Wong ${ }^{1}$
}

\begin{abstract}
Background: Postgraduate vocational training in family medicine (FM) is essential for physicians to build capacity and develop quality primary care. Inadequate standards in training and curriculum development can contribute to poor recruitment and retention of doctors in primary care. This study aimed to investigate: 1) the satisfaction level of doctors regarding vocational training in family medicine and associated demographics; and 2) the satisfaction level of doctors regarding their family medicine career and associated factors.
\end{abstract}

Method: This is a cross sectional study of all family medicine physicians across all government-funded primary care clinics (GOPCs). The study questionnaire consisted of items from a standardized and validated physician survey named the Physician Worklife Survey (PWS) (Konrad et al., Med Care, 1999). We selected three scales (7 items) relating to global job satisfaction, global career satisfaction and global specialty (family medicine) satisfaction with additional items on training and demographics. All significant variables in bivariate analyses were further examined using stepwise logistic regression.

Results: Out of 424 eligible family medicine physicians, 368 physicians successfully completed the questionnaire. The response rate was $86.8 \%$. Most participants were male (52.6\%), were aged between 35 and 44 years (55.5\%), were FM specialists (42.4\%), graduated locally (86.2\%), and had postgraduate qualifications. Eighty-two percent (82\%) of participants were satisfied with their training. Having autonomy and protected time for training were associated with satisfaction with FM training. Satisfaction with family medicine as a career was correlated with physicians' satisfaction with their current job. Doctors who did not enroll in training $(p<0.001)$ and physicians who were older $(p=0.023)$ were significantly less satisfied. Stepwise multivariate regression showed that doctors who subjectively believed their training as "broad and in depth' had higher career satisfaction $(p<0.001)$.

Conclusion: Overall, the satisfaction level of physicians on current family medicine training in Hong Kong was high. Having autonomy and protected time for training is associated with higher training satisfaction levels. Perceiving FM training as "broad and in-depth" is associated with higher family medicine career satisfaction.

Keywords: Doctors' satisfaction level, Vocational training, Family medicine training, Career satisfaction, Job satisfaction

\section{Background}

Postgraduate training in family medicine (FM) is essential for physicians to build their capacity and develop quality primary care. Inadequate standards in training and curriculum development may contribute to poor recruitment and retention of doctors in primary care [1]. In Hong Kong, students undertake an undergraduate medical

\footnotetext{
*Correspondence: carmenwong@cuhk.edu.hk

'JC School of Public Health and Primary Care, The Chinese University of Hong Kong, Sha Tin, Hong Kong

Full list of author information is available at the end of the article
}

degree as their first degree. Postgraduate family medicine training is provided by the Hong Kong College of Family Physician (HKCFP). The training of family medicine specialists in Hong Kong consists of 4 years of 'basic training' ( 2 years in hospital and 2 years in family medicine clinics in the community) and 2 years of 'higher training' in family medicine clinics (when trainees are required to conduct research or an audit, and learn clinic management and administration). Trainees receiving 'basic training' and 'higher training' are called 'basic trainees' and 'higher trainee' respectively. To obtain eligibility to enroll into

(c) The Author(s). 2019 Open Access This article is distributed under the terms of the Creative Commons Attribution 4.0 International License (http://creativecommons.org/licenses/by/4.0/), which permits unrestricted use, distribution, and reproduction in any medium, provided you give appropriate credit to the original author(s) and the source, provide a link to the Creative Commons license, and indicate if changes were made. The Creative Commons Public Domain Dedication waiver (http://creativecommons.org/publicdomain/zero/1.0/) applies to the data made available in this article, unless otherwise stated. 
higher training, basic trainees must pass the conjoint examinations organized by HKCFP and the Royal Australian College of General Practitioners (RACGP). Doctors with more than 5 years of experience in general practice can still apply for higher training after passing the co-joint examinations, and are not required to complete basic training [2]. Training is conducted primarily during training posts in general out-patient clinics (GOPCs), which are Government-funded clinics managed by the Hospital Authority (HA). Meanwhile, trainers are family medicine specialists appointed by the HKCFP [2]. Other doctors working in GOPCs include trained family medicine specialists and 'service doctors', who do not undergo formal vocational family medicine training.

In recent years, there has been increasing guidance for graduate medical education in family medicine which emphasizes training in terms of resources, programs and evaluation [3]. Meanwhile, family medicine career satisfaction has been associated with residency education that is broad and in depth [4]. The duration of postgraduate vocational FM training in Hong Kong is 6 years, which is longer than most programs where the specialty of family medicine is advanced, e.g., $2-4$ years training in Canada [5], US [6], UK [7] and Australia [8]. A qualitative study of vocational FM training in Hong Kong in 2010 revealed high variability in training standards and content, with limited training opportunities and heavy clinic workload [9]. A recent addition to the vocational program requires trainees to do research during their training, which is also present in other overseas training programs $[10,11]$. Almost all FM training is conducted in the public sector in GOPCs, with only a couple of trainees in FM training in private sector each year. The objectives of this study are to investigate: 1 ) the satisfaction level of doctors regarding vocational training in family medicine and associated demographics; and 2) the satisfaction level of doctors regarding their family medicine career and associated factors. This study will survey doctors working in the public sector in Hong Kong.

\section{Method}

This is a cross sectional study of family medicine physicians across all 73 GOPCs, which were divided into seven 'clusters' governed by HA. These clusters were pre-defined by the HA for resources allocation reasons; each cluster has an in-charge doctor to co-ordinate FM training. Questionnaires were sent to all doctors working in the GOPCs from May 2015 to January 2016. The questionnaires were delivered to training coordinators of the seven clusters of HA, and distributed by internal mail to individual doctors. All physicians were informed that the questionnaire would be anonymous and were instructed to return completed questionnaires directly to the study team (The Chinese University of Hong Kong) either by fax or through internal mail. An e-mail reminder was sent to all GOPCs doctors around 1-2 months after the first batch of questionnaires were sent out. Because it took time for questionnaires to be distributed and returned by internal mail, a second round of questionnaires was sent after 6 months. Physicians were encouraged to fill in the second questionnaire if they had not participated in the first round. Those eligible to participate included basic trainees, higher trainees, FM specialists, and service doctors as previously defined.

\section{Instrument - family medicine training satisfaction questionnaire}

The study questionnaire consisted of items from a standardized and validated physician survey named the Physician Worklife Survey (PWS) [12]. We selected three scales (7 items) relating to global job satisfaction, global career satisfaction and global specialty (family medicine) satisfaction (Additional file 2: Appendix 1). Additional items were based on questions by Young et al. [4] which were selected and adapted by the study team of family medicine physicians and academics. A pilot study of 10 family medicine trainees was conducted to ensure face and content validity. Responses were set at a 4-point Likert scale (strongly disagree, disagree, agree and strongly agree) (Additional file 2: Appendix 2). In addition, demographic information including sex, age, working location, place of graduation, postgraduate qualifications, trainee status, sessions of training in the past 12 months, and training modality were collected. Participants were also asked about the likelihood that they would recommend the training to others (on 10-point Likert scale).

\section{Data analysis}

Continuous variables were presented as mean \pm standard deviation and categorical variables as count and percentage. Two sample independent $t$ tests, ANOVA or Kruskal Wallis test were used for continuous variables, while chi-squared tests or Fisher Exact test for categorical variables. Physicians who responded with 'agree' or 'strongly agree' to the question 'I am satisfied with the training provided in GOPC setting over the last 12 months' were categorized as satisfied with the training and the proportion of doctors satisfied with training was the primary outcome. Those who were not satisfied with training were compared in terms of demographics and educational characteristics. Frequencies and descriptive statistics were computed on survey items. To investigate the independent factors of satisfaction on the training, all significant variables in the bivariate analyses with $p$-value of $<0.1$ were further examined using stepwise logistic regression. 
The secondary outcome variable was the sum of Likert scores from two questions on the PWS for family medicine career satisfaction: 'If I were to choose again, I would choose to be a family physician' and 'I would recommend family medicine to a student seeking advice'. Spearman correlation coefficients were used to evaluate bivariate relationships between Family Medicine Career Satisfaction Score and other continuous variables. The independent factors of the score were quantified using linear stepwise regression analysis.

Statistical analyses were performed using the statistical package SPSS version 21 (SPSS Inc., Illinois, US). Twotailed $p$-values at level of 0.05 or less were considered to be statistical significance. $95 \%$ Confidence intervals were provided wherever appropriate.

\section{Result}

Out of 424 eligible family medicine physicians, 368 successfully completed the questionnaire. Thus, the response rate was $86.8 \%$.

\section{Respondent characteristics}

Most participants were male (52.6\%), aged between 35 and 44 years (55.5\%), FM specialists (46.8\%), graduated locally $(86.2 \%)$ and had different levels of postgraduate qualifications (Table 1). Demographics of non-respondents could not be obtained.

There was heterogeneity in teaching modalities and amount of training sessions for different types of GOPC doctors (Additional file 1: Table S1a) and across clusters (Additional file 1: Table S1b). While basic and higher trainees received most training, more than $80 \%$ of

Table 1 Demographics, n (\%)

\begin{tabular}{|c|c|c|c|c|}
\hline & $\begin{array}{l}\text { Overall } \\
(n=368)\end{array}$ & $\begin{array}{l}\text { Service doctor } \\
(n=101)\end{array}$ & $\begin{array}{l}\text { Basic trainee / Higher trainee } \\
(n=108)\end{array}$ & $\begin{array}{l}\text { FM specialist } \\
(n=156)\end{array}$ \\
\hline \multicolumn{5}{|l|}{ Gender } \\
\hline Male & $191(52.6)$ & $70(69.3)$ & 37 (34.6) & $82(53.6)$ \\
\hline Female & $172(47.4)$ & $31(30.7)$ & $70(65.4)$ & $71(46.4)$ \\
\hline \multicolumn{5}{|l|}{ Age } \\
\hline $25-34$ & $102(28.2)$ & $11(11.0)$ & $80(75.5)$ & $11(7.1)$ \\
\hline $35-44$ & $201(55.5)$ & $36(36.0)$ & $25(23.6)$ & $140(90.9)$ \\
\hline 45 or above & $59(16.3)$ & $53(53.0)$ & $1(0.9)$ & $3(1.9)$ \\
\hline \multicolumn{5}{|l|}{ Cluster } \\
\hline A & $38(10.4)$ & $13(12.9)$ & $13(12.0)$ & $12(7.7)$ \\
\hline B & $55(15.0)$ & $3(3.0)$ & $23(21.3)$ & $29(18.7)$ \\
\hline$C$ & $33(9.0)$ & $14(13.9)$ & $7(6.5)$ & $12(7.7)$ \\
\hline$D$ & $35(9.5)$ & $21(20.8)$ & $8(7.4)$ & $5(3.2)$ \\
\hline E & $85(23.2)$ & $11(10.9)$ & $30(27.8)$ & $44(28.4)$ \\
\hline F & $68(18.5)$ & $22(21.8)$ & $11(10.2)$ & $34(21.9)$ \\
\hline G & $53(14.4)$ & $17(16.8)$ & $16(14.8)$ & 19 (12.3) \\
\hline \multicolumn{5}{|l|}{ Place of graduation } \\
\hline Hong Kong & $312(86.2)$ & $68(67.3)$ & $101(95.3)$ & $143(93.5)$ \\
\hline Outside Hong Kong & $50(13.8)$ & $33(32.7)$ & $5(4.7)$ & $10(6.5)$ \\
\hline \multicolumn{5}{|l|}{ Postgraduate qualifications (multiple answer) } \\
\hline FHKAM (FM) ${ }^{a}$ & $170(46.8)$ & $6(5.9)$ & $12(11.3)$ & $152(98.7)$ \\
\hline FHKCFPa & $210(57.9)$ & $23(22.8)$ & $47(44.3)$ & $139(90.3)$ \\
\hline FRACGP ${ }^{a}$ & $214(59.0)$ & $27(26.7)$ & $51(48.1)$ & $135(87.7)$ \\
\hline Diploma of FM & $114(31.4)$ & $28(27.7)$ & $25(23.6)$ & $59(38.3)$ \\
\hline Membership/fellowship of other international colleges/board of FM/GP & $26(7.2)$ & $9(8.9)$ & $9(8.5)$ & $8(5.2)$ \\
\hline Others & $24(6.5)$ & $11(10.9)$ & $7(6.5)$ & $6(3.8)$ \\
\hline
\end{tabular}

When the trainees finish basic training and passed conjoint examination, they are awarded FHKCFP/FRACGP. When the trainees pass higher training, they are awarded FHKAM (FM)

a FHKAM (FM) Fellow of the Hong Kong Academy of Medicine (Family Medicine), FHKCFP Fellow, Hong Kong College of Family Physicians, FRACGP The Fellowship of the Royal Australian College of General Practitioners 
Table 2 Satisfaction level and relationship with various attitudes; demographics

\begin{tabular}{|c|c|c|c|c|}
\hline & Total & $\begin{array}{l}\text { Satisfied } \\
(n=295,81.9 \%)\end{array}$ & $\begin{array}{l}\text { Unsatisfied } \\
(n=65,18.1 \%)\end{array}$ & $P$-value ${ }^{1}$ \\
\hline Global Job Satisfaction & $8.7 \pm 1.5$ & $9.1 \pm 1.2$ & $7.2 \pm 1.6$ & $<0.001$ \\
\hline Global Career Satisfaction & $6.4 \pm 1.0$ & $6.6 \pm 0.9$ & $5.8 \pm 1.2$ & $<0.001$ \\
\hline Family Medicine (Global) Specialty Satisfaction & $5.8 \pm 1.1$ & $6.0 \pm 1.0$ & $4.9 \pm 1.3$ & $<0.001$ \\
\hline \multicolumn{5}{|l|}{ Details of training } \\
\hline I was given a choice as to what kind training I can receive & & & & $<0.001$ \\
\hline Agree & $275(75.5 \%)$ & $253(86.1 \%)$ & $19(29.2 \%)$ & \\
\hline Disagree & $89(24.5 \%)$ & $41(13.9 \%)$ & $46(70.8 \%)$ & \\
\hline I do not have an adequate number of training sessions over the last 12 months ${ }^{a}$ & & & & $<0.001$ \\
\hline Agree & $139(38.8 \%)$ & $89(30.6 \%)$ & $49(76.6 \%)$ & \\
\hline Disagree & $219(61.2 \%)$ & $202(69.4 \%)$ & $15(23.4 \%)$ & \\
\hline I do not have protected time for training sessions ${ }^{\mathrm{a}}$ & & & & $<0.001$ \\
\hline Agree & $88(24.4 \%)$ & $53(18.1 \%)$ & $33(51.6 \%)$ & \\
\hline Disagree & $272(75.6 \%)$ & $240(81.9 \%)$ & $31(48.4 \%)$ & \\
\hline My training has prepared me to become a proficient doctor working in the GOPC & & & & $<0.001$ \\
\hline Agree & $315(87.0 \%)$ & $279(95.2 \%)$ & $34(52.3 \%)$ & \\
\hline Disagree & $47(13.0 \%)$ & $14(4.8 \%)$ & $31(47.7 \%)$ & \\
\hline My training was broad and in depth & & & & $<0.001$ \\
\hline Agree & $270(74.8 \%)$ & $248(84.9 \%)$ & $19(29.2 \%)$ & \\
\hline Disagree & $91(25.2 \%)$ & $44(15.1 \%)$ & $46(70.8 \%)$ & \\
\hline Likeliness to recommend the training received to others $(1-10)$, mean $\pm s d$ & $7.0 \pm 1.7$ & $1.8 \pm 0.4$ & $1.2 \pm 0.4$ & $<0.001$ \\
\hline $0-6$ & $106(29.3 \%)$ & $56(19.0 \%)$ & $48(76.2 \%)$ & $<0.001$ \\
\hline $7-10$ & $256(70.7 \%)$ & $239(81.0 \%)$ & $15(23.8 \%)$ & \\
\hline \multicolumn{5}{|l|}{ Demographics } \\
\hline Cluster & & & & 0.018 \\
\hline A & $38(10.4 \%)$ & $30(10.2 \%)$ & $8(12.3 \%)$ & \\
\hline B & $55(15.0 \%)$ & $50(17.0 \%)$ & $4(6.2 \%)$ & \\
\hline c & $33(9.0 \%)$ & $25(8.5 \%)$ & $8(12.3 \%)$ & \\
\hline D & $35(9.5 \%)$ & $33(11.2 \%)$ & $1(1.5 \%)$ & \\
\hline E & $85(23.2 \%)$ & $66(22.4 \%)$ & $18(27.7 \%)$ & \\
\hline $\mathrm{F}$ & $68(18.5 \%)$ & $47(16.0 \%)$ & $18(27.7 \%)$ & \\
\hline G & $53(14.4 \%)$ & $43(14.6 \%)$ & $8(12.3 \%)$ & \\
\hline Gender & & & & 0.453 \\
\hline Male & $191(52.6 \%)$ & $156(53.6 \%)$ & $31(48.4 \%)$ & \\
\hline Female & $172(47.4 \%)$ & $135(46.4 \%)$ & $33(51.6 \%)$ & \\
\hline Age & & & & 0.730 \\
\hline $25-34$ & $102(28.2 \%)$ & 85 (29.3\%) & $16(25.0 \%)$ & \\
\hline $35-44$ & $201(55.5 \%)$ & $157(54.1 \%)$ & $38(59.4 \%)$ & \\
\hline 45 or above & $59(16.3 \%)$ & $48(16.6 \%)$ & $10(15.6 \%)$ & \\
\hline Type of doctor & & & & 0.054 \\
\hline Service doctor & $101(27.7 \%)$ & $74(25.3 \%)$ & $25(38.5 \%)$ & \\
\hline Basic trainee / Higher trainee & $108(29.6 \%)$ & $93(31.8 \%)$ & $13(20.0 \%)$ & \\
\hline FM specialist & $156(42.7 \%)$ & $125(42.8 \%)$ & $27(41.5 \%)$ & \\
\hline Place of graduation & & & & 0.489 \\
\hline Hong Kong & $312(86.2 \%)$ & $249(85.6 \%)$ & $56(88.9 \%)$ & \\
\hline Outside Hong Kong & $50(13.8 \%)$ & $42(14.4 \%)$ & $7(11.1 \%)$ & \\
\hline
\end{tabular}

${ }^{1}$ Chi squared test

a The questions were negative questions, in which the answer 'agree' would be a negative answer and 'disagree' would be a positive answer. Figures may not add up to total $\mathrm{N}$ due to missing data 
Table 3 Comparison in satisfaction level of training for those who have attended different kinds of training modalities

\begin{tabular}{|c|c|c|c|c|c|c|}
\hline & \multicolumn{3}{|c|}{ Attended } & \multicolumn{2}{|c|}{ Not attended } & \multirow{2}{*}{$\begin{array}{l}P \text { - } \\
\text { value }^{2}\end{array}$} \\
\hline & $\overline{\mathrm{N}}$ & median $^{a}(\mathrm{QQR})$ & $\%$ of satisfied & $\overline{\mathrm{N}}$ & $\%$ of satisfied & \\
\hline Any modalities & 309 & $6(8.0)$ & 85.4 & 46 & 58.7 & $<0.001$ \\
\hline External courses & 141 & $4(3.0)$ & 87.9 & 214 & 78.0 & 0.018 \\
\hline Sit-in consultations & 100 & $3(5.8)$ & 89.0 & 255 & 79.2 & 0.031 \\
\hline Case discussion & 82 & $3(13.0)$ & 85.4 & 273 & 81.0 & 0.362 \\
\hline Video review & 81 & $3(3.0)$ & 86.4 & 274 & 80.7 & 0.236 \\
\hline SOPC attachment & 65 & $3(2.0)$ & 84.6 & 290 & 81.4 & 0.540 \\
\hline Practice management & 64 & $2(1.5)$ & 90.6 & 291 & 80.1 & 0.047 \\
\hline Research related & 46 & $2(5.0)$ & 84.8 & 309 & 81.6 & 0.595 \\
\hline TCM attachment & 4 & $2(0.8)$ & 75.0 & 351 & 82.1 & 0.550 \\
\hline
\end{tabular}

${ }^{2}$ Chi squared test or Fisher Exact test

${ }^{a}$ Median of number of modules attended

doctors received some form of training regardless of training status. Service doctors were more likely to have training via outside courses and SOPC attachments and higher trainees were more likely to receive research training. Cases, discussions and consultation skills feedback in terms of sit-in sessions and video reviews, were the most common training modalities (Table 3).

\section{Satisfaction of vocational training program}

Eighty-two percent (82\%) of participants were satisfied with their training. Around a quarter of respondents felt that they were not given a choice or enough time for their training and the training was not adequately broad or in depth (Table 2). Doctors who were dissatisfied with the training were more likely to also be dissatisfied with their clinical work $(p<0.001)$, their job as a medical doctor $(p<0.001)$, and their choice of being a family physician $(p<0.001)$. They were less likely to recommend working in GOPC to others and to students $(p<0.001)$ (Table 2). Doctors who attended external courses and sit-in consultations were more likely to be satisfied with FM training (Table 3).

In the regression analysis model (Table 4), satisfaction level regarding training was associated with job satisfaction (OR 2.2; 95\%CI: 1.5-3.2), likeliness to recommend the training to others (OR4.1; 95\%CI: 1.7-10.3), autonomy to training modalities (OR 11.2; 95\%CI: 4.6-27.1), been given protected time for training (OR 8.2;95\%CI: 3.2-21.4), and with training considered broad and in depth (OR 3.2; 95\% CI: 1.3-7.9).

\section{Satisfaction with family medicine as a specialty career}

Around $19 \%$ of participants would not want to work in their current job (GOPC) nor be a family physician given the choice, while 9\% would rethink their career as a doctor given the chance [data not shown]. Older doctors $(p=0.023)$ and service doctors $(p<0.001)$ had significantly lower satisfaction levels. In the regression model, high job satisfaction $(p<0.001)$, autonomy to training modalities $(p=0.034)$, received training which is considered broad and in depth $(p<0.001)$ and have enrolled in FM training $(p<0.001)$ were associated with higher career satisfaction (Table 5).

\section{Discussion}

Overall satisfaction with the current FM training was high at $82 \%$ - a level of satisfaction comparable to or even higher than those reported in international studies. Although initial reports from the United Kingdom showed that around half of trainees were unsatisfied with their training in the early 1990s [1], subsequent efforts to improve the training [13] appears to have paid off, and the latest figures showed that more than

Table 4 Stepwise logistic regression model for satisfaction in regards to the training received in $\mathrm{GOPC}$

\begin{tabular}{ll}
\hline Global Job Satisfaction & OR $(95 \% \mathrm{Cl})$ \\
\hline
\end{tabular}

Likeliness to recommend the training received to others

$\begin{array}{ll}\text { Score } 0-6 & 1 \\ \text { Score } 7-10 & 4.1(1.7-10.3)\end{array}$

Details of training

I was given a choice as to what kind of training I can receive

$\begin{array}{ll}\text { Disagree } & 1 \\ \text { Agree } & 11.2(4.6-27.1)\end{array}$

I do not have an adequate number of training sessions over the last 12 months $^{\text {a }}$

$$
\begin{array}{ll}
\text { Agree } & 1 \\
\text { Disagree } & 8.2(3.2-21.4) \\
\text { My training was broad and in depth } & \\
\text { Disagree } & 1 \\
\text { Agree } & 3.2(1.3-7.9)
\end{array}
$$

a The questions were negative questions, in which the answer 'agree' would be a negative answer and 'disagree' would be a positive answer 
Table 5 Association between family medicine (global specialty) career satisfaction score and various attitudes; demographics

\begin{tabular}{|c|c|c|c|c|}
\hline & \multicolumn{2}{|c|}{ Bivariate association } & \multicolumn{2}{|c|}{$\begin{array}{l}\text { Stepwise Multivariate regression } \\
\text { (adj. } R^{2}=0.539 \text { ) }\end{array}$} \\
\hline & Spearman's $r$ & p-value & Standardized Beta & $p$-value \\
\hline Global Job Satisfaction & 0.589 & $<0.001$ & 0.487 & $<0.001$ \\
\hline Global Career Satisfaction & 0.405 & $<0.001$ & & \\
\hline \multicolumn{5}{|l|}{ Details of training } \\
\hline I am satisfied with the training provided in GOPC setting over the last 12 months & 0.437 & $<0.001$ & & \\
\hline I was given a choice as to what kind training I can receive & 0.384 & $<0.001$ & 0.096 & 0.034 \\
\hline I do not have an adequate number of training sessions over the last 12 months ${ }^{a}$ & 0.150 & 0.004 & & \\
\hline I do not have protected time for training sessions ${ }^{a}$ & 0.144 & 0.006 & & \\
\hline My training has prepared me to become a proficient doctor working in the GOPC & 0.486 & $<0.001$ & & \\
\hline My training was broad and in depth & 0.465 & $<0.001$ & 0.214 & $<0.001$ \\
\hline \multirow[t]{2}{*}{ Likeliness to recommend the training received to others $(1-10)$} & 0.469 & $<0.001$ & & \\
\hline & mean $\pm s d^{c}$ & $p$-value ${ }^{2}$ & & \\
\hline \multicolumn{5}{|l|}{ Demographics } \\
\hline Cluster & & 0.029 & & \\
\hline A & $5.8 \pm 1.2$ & & & \\
\hline B & $6.1 \pm 1.0$ & & & \\
\hline$c^{b}$ & $5.2 \pm 1.2$ & & & \\
\hline $\mathrm{D}$ & $5.8 \pm 1.1$ & & & \\
\hline E & $5.9 \pm 1.2$ & & & \\
\hline $\mathrm{F}$ & $5.8 \pm 1.0$ & & & \\
\hline G & $6.0 \pm 1.2$ & & & \\
\hline Gender & & 0.125 & & \\
\hline Male & $5.7 \pm 1.2$ & & & \\
\hline Female & $5.9 \pm 1.1$ & & & \\
\hline Age & & 0.023 & & \\
\hline $25-34$ & $5.9 \pm 1.0$ & & & \\
\hline $35-44$ & $5.9 \pm 1.2$ & & & \\
\hline 45 or above ${ }^{b}$ & $5.4 \pm 1.2$ & & & \\
\hline Type of doctor & & $<0.001$ & 0.181 & $<0.001$ \\
\hline Service doctor ${ }^{\mathrm{b}}$ & $5.4 \pm 1.2$ & & & \\
\hline Basic trainee / Higher trainee & $5.9 \pm 1.1$ & & & \\
\hline FM specialist & $6.0 \pm 1.1$ & & & \\
\hline Place of graduation & & 0.357 & & \\
\hline Hong Kong & $5.9 \pm 1.1$ & & & \\
\hline Outside Hong Kong & $5.7 \pm 1.3$ & & & \\
\hline
\end{tabular}

${ }^{2}$ ANOVA or independent two samples t test

ascales inverted

${ }^{\mathrm{b}}$ Significant different from other groups

${ }^{c}$ mean $\pm \mathrm{sd}$ of Family Medicine (Global Specialty) Career Satisfaction Score

80-90\% of doctors felt satisfied with their training and work [14-16]. Similarly, high levels of satisfaction with training, ranging from more than 80 to $90 \%$, was found in a survey conducted in Ireland [17]. A more recent report from Dublin also found that only $1 \%$ of trainees indicated that they regretted training as a general practitioner [18]. By contrast, a survey conducted in the United States in 2008 found that only half of doctors who graduated within 10 years were satisfied with being a family physician and that satisfaction was related to the characteristics of the training program [4]. 
This study found that doctors who were given choices related to the training content and modalities, had higher training satisfaction. Future studies could explore if enhancing trainee's autonomy to tailor the details of their training can enhance their satisfaction with their training and career. Meanwhile, doctors who were unsatisfied with their training were more likely to feel that they had an inadequate number of training sessions, that the training has not made them a proficient doctor working in GOPC, and be unsatisfied with their clinical work. As a weakness shared by all survey studies, it is not possible to determine if the doctors were unsatisfied with the training and therefore did not want to work in GOPC or whether the reverse was true: or that the doctors disliked working in GOPC and therefore were unsatisfied with the training, which was mostly conducted in GOPC. Lastly, this study also echoes previous studies that the training provided depends on location and individual trainers [9].

Furthermore, the current study agrees with the previous literature that good FM training programs are interlinked with good career satisfaction [4]. As with previous studies, this research reveals that FM doctors who considered their training as 'broad and in-depth', had higher career satisfaction [4]. In this study, service doctors were least satisfied with their career and many characteristics of training were associated with career satisfaction (Table 5). A worrisome finding is that around one-fifth of doctors regretted training as an FM doctor and around one-tenth would choose to rethink their career as a doctor, given the chance. We hypothesize that this could be due to the well-reported phenomenon of burnout in doctors [19, 20], but can only be determined in future studies.

As family medicine training programs are gaining in popularity [21], satisfaction surveys should be conducted as a part of a regular evaluation of the quality of training programs. As 'no curriculum is perfect in design and delivery', regular evaluation including satisfaction levels can help to 'correct the deficiencies in a continuous and updated manner' [22]. In fact, periodic satisfaction research or survey is conducted in countries such as the United Kingdom and Australia [14-16, 23, 24]. Satisfaction research can also be repeated after important changes are introduced in the training program to assess the impact of changes [24]. Specific instruments are being developed to measure satisfaction on different aspects of training in some countries [17, 22]. Future surveys may look further into satisfaction towards training in hospitals because there are discrepancies in the effects of hospital training on satisfaction $[1,14,18]$. Others unexplored factors that may be associated with satisfaction include: degree of feedback $[17,23]$ availability of hand-on experience [4, 23], psychological impact [25], and the use of logbooks [23].

\section{Strength and weakness}

To the authors' knowledge, this is the first quantitative study in primary care in Asia to describe the satisfaction of doctors towards their vocational training in family medicine. The sample size was adequate and satisfaction levels were found to be associated with a number of attitudes listed in Tables 2, 3 and 5. A baseline level on satisfaction level of family medicine training is now established and future surveys can be used to monitor and evaluate changes in satisfaction levels, especially after changes are implemented in the training curriculum. In addition, use of validated instruments enabled our exploration of satisfaction with training as well as satisfaction of family medicine specialty career.

Yet, the cross-sectional design of the current study did not allow us to draw causal conclusions and can be prone to recall bias. While the survey was anonymous, the location of GOPC was known as the survey was mailed back by internal mail. Participants may also report higher satisfaction with training or their FM career due to social desirability. Although the study achieved an acceptable response rate of $86.8 \%$, we could not obtain non-respondents' characteristics and; therefore, our findings may not be generalisable. In addition, limitations related to sample size contributed to wide confidence intervals and imprecise effect size estimation.

\section{Conclusion}

The overall satisfaction level of physicians towards current family medicine training in Hong Kong is high. Having autonomy, protected time, external courses and individual feedback in sit in consultations $\mathrm{s}$ associated with higher training satisfaction levels. Finally having adequate breadth and depth of family medicine training is associated with family medicine career satisfaction.

\section{Supplementary information}

Supplementary information accompanies this paper at https://doi.org/10. 1186/s12875-019-1030-8

\footnotetext{
Additional file 1: Table S1. a. Number of training sessions within protected time in the past 12 months by trainee status. b. Number of training sessions within protected time in the past 12 months by cluster $(n=363)$.

Additional file 2: Appendix 1. Selected items from the Physician Worklife Survey (PWS). Appendix 2. Finalized questionnaire.

Abbreviations

FHKAM (FM): Fellow of the Hong Kong Academy of Medicine (Family Medicine); FHKCFP: Fellow, Hong Kong College of Family Physicians;

FM: Family medicine; FRACGP: The Fellowship of the Royal Australian College of General Practitioners; GOPCs: Government Primary Care Clinics;

HA: Hospital Authority; HKCFP: Hong Kong College of Family Physician; PWS: Physician Worklife Survey; RACGP: Royal Australian College of General Practitioner
}

Acknowledgements Not applicable. 


\section{Authors' contributions}

KPL, DChan, KK, LL and SYSW were responsible for the literature review section. They also contributed to creating and organizing the figures, as well as the design for the above study. In addition, they were involved in the data collection, data analysis, data interpretation, and writing the manuscript. While MCSW and CW were also involved in the study design, they had a different focus. MCSW focused on the literature review and figures sections, and $\mathrm{CW}$ was involved in data analysis, data interpretation and writing the manuscript. Co-authors DChao, VL, CWC, WK, TFL, YHC, and HTF, MKL were employees of the Hospital Authority. They were involved in the study design and logistics, but had no involvement in data analysis and interpretation. All authors read and approved the final version of the manuscript.

\section{Funding}

The work described in this paper was fully supported by a grant from the Food and Health Bureau of the Government of the Hong Kong Special Administrative Region (Project Ref. EPC-CUHK, Ref no.: FHB/H/41/31). The Funding body has no role in any part of the study.

\section{Availability of data and materials}

The datasets used and/or analyzed during the current study are available from the corresponding author on reasonable request.

\section{Ethics approval and consent to participate}

Ethics approval from Survey and Behavioural Research Ethics Committee (SBREC) Ref: $F H B / H / 41 / 25$. Since this was an anonymous survey, consent from respondent was given in the form of implied consent. SBREC is affiliated to the Chinese University of Hong Kong.

\section{Consent for publication}

Not applicable.

\section{Competing interests}

Samuel Yeung Shan Wong is a member of the editorial board (Associate Editor) of BMC Family Practice. All other authors declare that they have no competing interests.

\section{Author details}

${ }^{1} \mathrm{JC}$ School of Public Health and Primary Care, The Chinese University of Hong Kong, Sha Tin, Hong Kong. ${ }^{2}$ Hospital Authority, Hospital Authority Building, 147B Argyle Street, Kowloon, Hong Kong.

\section{Received: 21 January 2019 Accepted: 24 September 2019}

\section{Published online: 20 October 2019}

\section{References}

1. Orton P, Qureshi B. GP vocational training in the UK. J R Soc Med. 1994:87: 119.

2. Wun YT, Lam TP, Lam KF, Li DKT, Yip KC. Family medicine training in Hong Kong: similarities and differences between family and non-family doctors. Hong Kong Med J. 2011;17:47-53.

3. Accreditation Council for Graduate Medical Education (ACGME). ACGME program requirements for graduate medical education in family medicine. 2016. https://www.acgme.org/Portals/O/PFAssets/ProgramRequirements/12 0_family_medicine_2016.pdf. Accessed 21 Apr 2017.

4. Young R, Webb A, Lackan N, Marchand L. Family medicine residency educational characteristics and career satisfaction in recent graduates. Fam Med. 2008:40:484-91.

5. Balaban D. Family medicine in Canada. Future of family medicine 2013. http://futureoffamilymedicine.blogspot.hk/2013/04/family-medicine-incanada.html. Accessed 21 Apr 2017

6. American Academy of Family Physicians (AAFP). Family medicine: comprehensive care for the whole person -- choosing family medicine. http://www.aafp.org/medical-school-residency/choosing-fm/model.html. Accessed 21 Apr 2017

7. Royal College of General Practitioners (RCGP). How to become a GP. http:// www.rcgp.org.uk/training-exams/becoming-a-gp/how-to-be-a-gp.aspx. Accessed 21 Apr 2017

8. Gupta TS, Hays R. Training for general practice: how Australia's programs compare to other countries. Aust Fam Physician. 2016;45:18-21.
9. Kung K, Wong SYS, Wong C, Wong M, Gao T, Griffiths SM. Family medicine training in Hong Kong's public health care system: a focus group study. Hong Kong Pract. 2011;33:97-106.

10. Carek PJ, Mainous AG III. The state of resident research in family medicine: small but growing. Ann Fam Med. 2008;6(Suppl 1):S2-4. https://doi.org/10. 1370/afm.779.

11. Bolon SK, Phillips RL. Building the research culture of family medicine with fellowship training. Fam Med. 2010:42:481-7.

12. Konrad T, Williams E, Linzer M, McMurray J, Pathman DE, Gerrity M, Schwartz MD, Scheckler WE, Van Kirk J, Rhodes E, et al. Measuring physician job satisfaction in a changing workplace and a challenging environment. Med Care. Published online first: 1999. http://www.jstor.org/stable/3767071. Accessed 21 Apr 2017.

13. Evans J, Lambert T, Goldacre M. GP recruitment and retention: a qualitative analysis of doctors' comments about training for and working in general practice. Occas Pap R Coll Gen Pract. 2002;iii-vi:1-33.

14. General Medical Council UK (GMCUK). National training survey 2014. http:// www.gmcuk.org/National_training_survey_2014_key_findings_report_1114. pdf 58504492.pdf. Accessed 3 Mar 2017.

15. Watson J, Humphrey A, Peters-Klimm F, Hamilton W. Motivation and satisfaction in GP training: a UK cross-sectional survey. Br J Gen Pract. 2011; 61(591):e645-9.

16. Millett D. GP trainees report higher satisfaction than other specialties GPonline. GP Bull. 2016; http://www.gponline.com/gp-trainees-reporthigher-satisfaction-specialties/article/1402387. Accessed 3 Mar 2017.

17. Mulrooney A. Development of an instrument to measure the practice vocational training environment in Ireland. Med Teach. 2005;27:338-42. https://doi.org/10.1080/01421590500150809.

18. O'Kelly M, O'Kelly F, Ciardha DÓ. A national survey of GP trainees 2012. https://www.tcd.ie/medicine/public_health_primary_care/assets/pdf/ NatSurv-GP-Trainees-2012.pdf. Accessed 3 Mar 2017.

19. McCray LW, Cronholm PF, Bogner HR, Gallo JJ, Neill RA. Resident physician burnout: is there hope? Fam Med. 2008:40:626-32.

20. Shanafelt TD, Hasan O, Dyrbye LN, Sinsky C, Satele D, Sloan J, West CP. Changes in burnout and satisfaction with work-life balance in physicians and the general US working population between 2011 and 2014. Mayo Clin Proc. 2015;90:1600-13.

21. Jenn Ng C, Lieng Teng C, Abdullah A, Hoong Wong C, Sherina Hanafi N, Su Yin Phoa S, Tong WT. The status of family medicine training programs in the Asia Pacific. Fam Med. 2016;48:194-202.

22. Al-Khathami AD. Evaluation of Saudi family medicine training program: the application of CIPP evaluation format. Med Teach. 2012;34:S81-9. https:// doi.org/10.3109/0142159X.2012.656752.

23. Paice $E_{\text {, Aitken } M}$, Cowan $G$, Heard $S$. Trainee satisfaction before and after the Calman reforms of specialist training: questionnaire survey. BMJ. 2000; 320:832-6. https://doi.org/10.1136/bmj.320.7238.832.

24. Department of Health, Australian Government. Registrar satisfaction survey australian general practice training. 2015. http:/www.agpt.com.au/GPregistrars/Registrar-Satisfaction-Survey. Accessed 6 Mar 2017.

25. Larkins SL, Spillman M, Vanlint JW, Hays RB. Stress, personal and educational problems in vocational training. A prospective cohort study. Aust Fam Physician. 2003;32(6):473-5.

\section{Publisher's Note}

Springer Nature remains neutral with regard to jurisdictional claims in published maps and institutional affiliations.

Ready to submit your research? Choose BMC and benefit from:

- fast, convenient online submission

- thorough peer review by experienced researchers in your field

- rapid publication on acceptance

- support for research data, including large and complex data types

- gold Open Access which fosters wider collaboration and increased citations

- maximum visibility for your research: over $100 \mathrm{M}$ website views per year

At $\mathrm{BMC}$, research is always in progress.

Learn more biomedcentral.com/submission 